\title{
APPRECIATION OF CHINESE CALLIGRAPHY *
}

\author{
BY WANG FANG YU \\ Mr. Wang is a calligrapher living in Short Hills, N.J. \\ I. Calligraphy and Chinese Calligraphy
}

Calligraphy means "artistic writing." Writing involves written language and a written language involves a writing system. Of the world's existing writing systems, there are basically three different types: phonetic, as in English; syllabic, as in Japanese kana; and logographic. The Chinese writing system is unique and is the only one that is logographic. Logographs involve meaning. Meaning is always complicated. So logographs in writing have to be numerous.

Nobody knows when Chinese writing started. In 1985 and 1986, near the city of Xi'an, China, ancient characters carved on bones were found. These bone objects have been dated to 2500 B.C. Already at that time the forms of the characters were quite sophisticated.

How many characters are there in the Chinese writing system? The largest dictionary contains more than one hundred thousand characters. The contemporary daily-used characters number over three thousand.

In English, there are printed forms and handwritten forms. In Chinese, because of the long history of writing, the handwritten forms have evolved into at least seven general categories:

1. In 1899, at the Shang dynasty capital Yin, near the city of Anyang in Henan province, a large cache of bones and turtle shells was unearthed. The bones and shells with writings carved on them were used for divination in about the 13th century B.C. Over four thousand different characters were found. These characters have been called "oracle bone form."

2. Before the Qin dynasty (221-207 B.C.), characters cast in bronze or carved on stone have been preserved. These character forms were called "Great Seal form."

3. In the year 221 B.C., following the unification of China, the emperor Shihuangdi tried to unify the forms of the characters. The resulting characters were called "Small Seal forms" and show rounded corners as their distinctive feature.

- This is the text of a talk given by the author on the occasion of the opening of the exhibition on "Chinese Calligraphy" at Alexander Library in April 1990. 
A Chart Showing the Evolution of the Character for "Dragon"
1. Oracle
2. Great 3. Small
4. Clerical
5. Regular
6. Running 7. Cursive bone seal seal
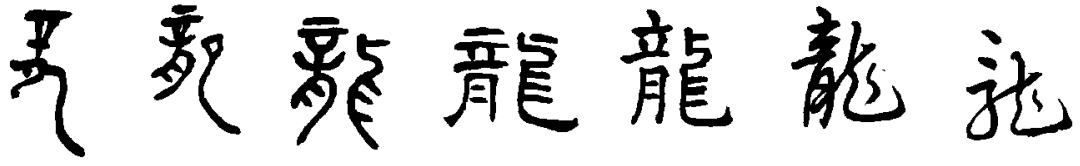

4. While the unified forms were used in official documents, another form with square corners - somewhat easier to write-was in use by scholars and the common people. This was called the "Clerical form."

5. The contemporary "regular form" was started about A.D. 300. More complicated stock forms were used in this style.

6. About the same time a "Running form" was created. This "running form" is close to the "regular form" but features connective lines between the strokes. Running form is distinguished from cursive script by its closeness to the regular form and its lack of simplification.

7. In the second century B.C., a kind of "cursive script" developed. At first it was only a natural practice to connect strokes together, similar to English "A" written as " 4 ." Later the characters took on a standard simplified form (see Chart).

If we use the three thousand basic characters as a basis, each character may be written in any of the seven forms, yielding, at least, 21,000 different forms for a Chinese calligrapher to deal with. In contrast, the twenty-six letters in English plus their different forms may yield only about a hundred or so forms.

The large number of characters with their various forms, each with a unique structure, provides a vast amount of raw material for the calligrapher. Chinese calligraphy is thus much more complicated than the calligraphy in any other language.

Chinese calligraphy and Chinese painting make use of the same implements. The combination of the flexible rounded, conical brush, absorbent paper, and water-based glue and soot ink produce a unique effect for Chinese calligraphical art. The lines and dots may vary in appearance, as all are produced by the technique of one stroke without retouching. It takes a lot of practice to control the brush and produce a perfect stroke.

Chinese philosophical thought underlies the forms of writing and creates a depth which contributes to an appreciation transcending mere visual enjoyment. Confucianism or Daoism gives the calligrapher the background 


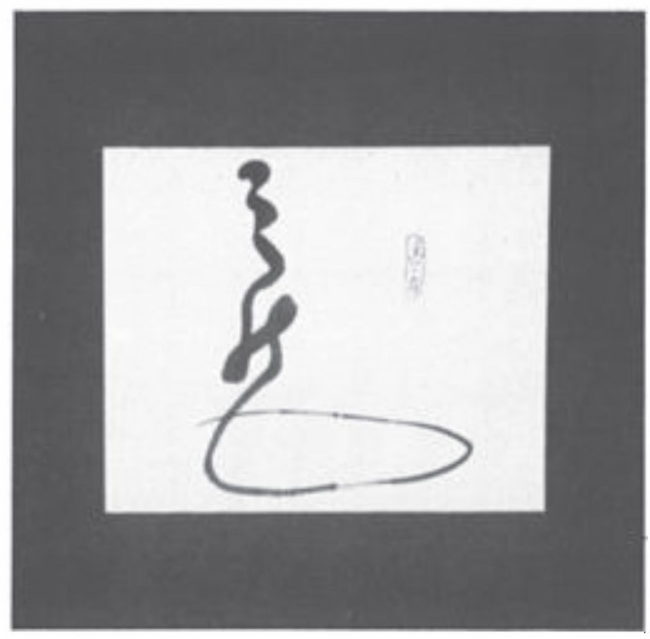

"Dragon"

An item of calligraphy by the author shown in the exhibit of Chinese Calligraphy at Alexander Library in April 1990. This character is a transformation of the form No. 7 in the chart.

to create the forms which are suitable to his thought. Either restrained (but suggestive), or unrestrained, the calligrapher can always find his philosophical foundation. Confucianism stresses self-control, and well-mannered behavior. Based on these characteristics, one's writings should appear like a well-mannered person who exhibits considerable self-control but is never showing off. Daoism, or the teaching of Laozi and Zhuangzi, emphasizes nature. According to this school, the calligrapher should produce spontaneous forms to express his individual feelings.

\section{Analysis of Chinese Calligraphy}

1. Stroke forms-dots and lines

The strokes, which are the building blocks of characters, differ in the seven forms. In the regular form, strokes are the most sophisticated. They are horizontal or vertical, slanting from top-right to bottom-left, or from topleft to bottom-right. The beginning and the end of certain strokes require particular shapes. For a certain stroke to end, a point is required. Dots also differ in their forms.

2. Structure of the characters

Each of the characters may be considered as an individual picture with its own structure, gesture, movement and spirit. 
3. Lines formed by characters

Generally speaking, the lines are formed from top to bottom in straight columns. But in an artistic production the characters should not be so mechanically placed.

4. Composition

Traditionally, there are not many variations in calligraphical composition. Formats are limited to hanging scrolls, hand scrolls, albums, fans, couplets, and a set of four, six or eight hanging scrolls forming a panel. They all consist of vertical lines of characters. Only recently has the "fewer-character" format become popular. A piece in this style may contain only a single character, or be formed of only a few characters, and the shape of the calligraphical composition comes into play more so than in the traditional works.

\section{Calligraphy vis-à-vis Natural Phenomena}

\section{Unity}

The universe is a unified entity and, moreover, is composed of innumerable sub-units, each of which is in itself a complete entity. This is also true of calligraphy. A piece of calligraphy is a unified entity. It is composed of lines of characters and the characters are composed of different strokes. Each stroke is a unified entity.

2. Change

Man, long ago, perceived change in nature. The ancient Chinese created the Book of Change, probably in the 8th century B.C. or earlier. Change is the basic process of the whole universe.

Some of the line and dot variations in Chinese calligraphy are striking in appearance; others are barely visible in the brushwork-the lightness or heaviness of the touch, speed and restraint, compositional looseness or density, largeness or smallness of size-all seek to become integrated within the variations to form a unified whole.

\section{Continuity}

From the beginning, man noticed cyclical change in the world, such as day becoming night, and season following season. Continuous motion was very evident. The principle of continuity as demonstrated in Chinese calligraphy is also very clear. From the first stroke to the last, one character at a time, line by line down to the last stroke, Chinese calligraphers stress the continuity of spirit. A single stroke may appear to be a broken line, but since it was done in one motion, the broken line has a spirit of continuity. 


\section{Motion}

Whether it is the movement of the celestial bodies or the growth and propagation of the world's plants and animals, the phenomenon of movement and force is visible everywhere.

Motion and tranquility are two opposing phenomena. In Chinese art, there is a conscious mingling of the two to get the feeling of "tranquility in motion and motion in tranquility." The highest level of Chinese calligraphy is achieved by Wang Xizhi's (c.307-c.365)work, which exhibits not only tranquility on the surface but also an internal motion.

5. Balance

Equilibrium is not the same as symmetry. Comets in the sky are examples of assymmetrical equilibrium. The phenomenon of symmetry in the world is extremely common. Chinese calligraphers, in seeking equilibrium from assymmetry, are offering people a feeling of liveliness. Unbalanced balance is the aim of the calligrapher.

6. Rhythm

Rhythm is the active process of movement of continuity to an organized pattern.

The sound of flowing water, the wind blowing though a pine grove, the singing of birds, the chirping of crickets, the neighing of horses-each has its distinctive rhythm.

Aside from sounds, snakes slither, rabbits hop, birds soar, fish swim, horses gallop, apes swing-all in their natural rhythm.

In calligraphy, regardless of whether the form is regular, cursive, clerical, or seal style, from individual brushstroke to the finished whole, rhythm is manifest. The calligraphers all attempt to transpose nature's rhythm into a calligraphic rhythm.

\section{Communication between the Calligrapher and the Viewer}

As in any visual art, the viewer may be attracted or annoyed at first sight. People may say: "It is beautiful" or "I like it." It may mean something, but in most cases it does not. The superficial acceptance is good enough for decorative purposes, but holds no deeper meaning. A good piece of calligraphy has to show its spirit so that the more the viewer looks at it, the more its deeper quality will show through. However, the highest level of relationship between a piece of calligraphy and a viewer evokes a feeling that the piece of art is continuously talking to the viewer, supplying him with the thoughts that he needs. Enjoying a piece of calligraphy is similar to making a friend. There may be some pieces that you don't want to be friendly with. Some will 
cause you to fall in love at first sight. Others may repel you at first, but gradually win you over as their true character is revealed over time. It is this third kind of friendship which is lasting.

In our busy modern times it is not easy to enjoy Chinese art. It is an art which is not meant to excite people but is made to create feelings of tranquility, peace, and harmony. Chinese art cannot compete with the sensationalism, terror, and excitement of our television programs. But, somehow, it stands all by itself and will probably last longer than any of the television programs. To enjoy a piece of calligraphy, the first step is to open up and try to let the spirit of the calligraphy enter your soul. Let the calligraphy talk to you. Try to find a piece which you can hear or feel. Then, respond to it. Mingle your feelings with the spirit of the piece. One viewer whom I have never met wrote me after she attended my exhibition in San Francisco. She wrote "You opened my eyes, warmed my heart, and sent me home with new vitality." This is true communication.

The appreciation of calligraphy is different depending on the degree of insight into the history of Chinese calligraphy and a knowledge of the writing system possessed by the viewer. Those who cannot read Chinese may find it easier to uncover the artistic point of a particular work. When a person who can read Chinese and has been trained in the history of calligraphy encounters a new work, he may first think about which master has influenced the calligrapher. Next he will try to read the content of the piece. These two tasks will attract all his attention, and he may miss the aesthetic points noticed by the less "sophisticated" viewer. The most important point of appreciation is the communication between the calligraphy and the audience. It really does not matter that the viewer may or may not be able to read the content of the piece. It is the spirit beyond the forms which is the center of appreciation.

To illustrate this point, a story from Liezi is quoted here. Duke $\mathrm{Mu}$ (659-621 B.C.) of the state of Qin asked Jiufang Gao to find him a good horse. Jiufang Gao had been introduced to him by Bolao as an expert on judging horses. When Jiufang came back to report, Duke Mu asked what kind of horse he had found, and what its gender and color was. Jiufang said, "It is a black male horse." Yet when his horseman reported to the Duke, the horse turned out to be a brown mare. Duke Mu was very unhappy and said to Bolao, "Jiufang cannot even tell the color and gender of a horse." But Bolao replied: "What Jiufang saw was the spirit of the horse, which goes beyond the color and gender." When the horse was presented to the Duke, it was indeed a truly magnificent beast. 